\title{
Studies on $\mathrm{CuCe}_{0.75} \mathrm{Zr}_{0.25} \mathrm{O}_{x}$ preparation using bacterial cellulose and its application in toluene complete oxidation
}

\author{
Ningna Yan, ${ }^{[a]}$ Qinglan Hao, ${ }^{[a]}$ Chenchen Zhao, ${ }^{[a]}$ Deyu Yang, ${ }^{[a]}$ Baojuan Dou, ${ }^{\text {[a] }}$ K.S. \\ Hui, ${ }^{[}{ }^{[b]}$ and Kwun Nam Hui, ${ }^{[c]}$
}

\begin{abstract}
A series of $\mathrm{CuCe}_{0.75} \mathrm{Zr}_{0.25} \mathrm{O}_{x}$ catalysts (CCZ) were synthesized based on the environmental-friendly bacterial cellulose $(\mathrm{BC})$ by using the sol-gel method. The corresponding synthesis mechanism, physicochemical properties of the catalysts and catalytic performances for toluene oxidation were comprehensively studied. In the presence of $B C$ without sugar, the CCZ-A synthesized by ethanol-gel exhibits better catalytic activity than the CCZ-W synthesized by water-gel, which may be due to the different roles of $B C$ in different solvents. However, it is worth noting that the graft copolymerization between BC and active metal $\left(\mathrm{Ce}^{4+}, \mathrm{Cu}^{2+}\right)$ is the same process in both water-gel and ethanol-gel. The activity of CCZ-SW synthesized by water-gel using $B C$ with sugar is obviously higher than that of CCZ-W and CCZ-A. The temperature of complete degradation of toluene over CCZ-SW is $205^{\circ} \mathrm{C}$, which is $35^{\circ} \mathrm{C}$ lower than that of CCZ-W. The results from $B E T$, Raman and $\mathrm{H}_{2}$-TPR indicate that the larger the specific surface area, the more oxygen vacancies and better low-temperature reducibility, that are mainly responsible for the excellent activity of CCZ-SW. The existence of sugar in BC could hinder the agglomeration of active metal particles during the calcination process. Combined with the results of in situ DRIFT, the adsorbed toluene on the catalyst surface is oxidized into alkoxide, aldehydic and carboxylic acid species as intermediates before the complete oxidation into $\mathrm{CO}_{2}$ and $\mathrm{H}_{2} \mathrm{O}$.
\end{abstract}

\section{Introduction}

Toluene, a kind of typical volatile organic compounds (VOCs), originating from artificial and industrial sources, is proved to cause serious environmental problems, diverse diseases and partial chromosome variation in humans due to its carcinogenic, mutagenic and teratogenic characteristics. ${ }^{[1-3]}$

[a] N. Yan, Q. Hao, C. Zhao, D. Yang, Prof. B. Dou Tianjin University of Science \& Technology, Tianjin 300457, P.R. China

E-mail: bjdou@tust.edu.cn

[b] Prof. K.S. Hui

Engineering, Faculty of Science, University of East Anglia, Norwich Research Park, NR4 7TJ, UK

[c] Prof. K.N. Hui

Institute of Applied Physics and Materials Engineering, University of Macau, Avenida da Universidade, Taipa, Macau, China
Among general VOCs removal techniques, catalytic oxidation is an effective and economical technology for VOCs abatement, aiming complete destruction of VOCs rather than changing it into another phase. ${ }^{[4,5]}$ Transition metal oxides $\left(\mathrm{CO}_{3} \mathrm{O}_{4}, \mathrm{FeO}, \mathrm{CuO}, \mathrm{MnO}_{2}\right.$, etc) are typical catalysts for toluene oxidation than noble metal catalysts, having the properties of low-cost, high activity and resistance to poisoning. ${ }^{[6-9]}$ Copper oxide catalysts show high catalytic activity for VOCs combustion. ${ }^{[7,10,11]}$ However, the copper oxide catalysts with a high light-off temperature are easily sintered during the VOCs oxidation. Fortunately, adding metal-promoter $\left(\mathrm{CeO}_{2}, \mathrm{ZrO}_{2}\right.$, etc $)$ can significantly improve the catalytic performance of copper oxides. $\mathrm{CeO}_{2}$, possessing a relatively high mobility of oxygen species, shows an excellent oxygen storage capacity that was due to the conversion between $\mathrm{CeO}_{2}$ and $\mathrm{Ce}_{2} \mathrm{O}_{3}\left(\mathrm{Ce}^{4+}\right.$ and $\left.\mathrm{Ce}^{3+}\right) \cdot{ }^{[12]}$ Moreover, $\mathrm{CuO}-\mathrm{CeO}_{2}$ mixed metal oxides have showed high catalytic activity for toluene combustion, and the addition of $\mathrm{ZrO}_{2}$ into the catalysts can enhance the thermal stability. ${ }^{[13]}$

It is well known that the structural properties of $\mathrm{Cu}-\mathrm{Ce}-\mathrm{Zr}$ catalyst can be influenced by the preparation methods. Many methods have been used to synthesize the metal oxides including co-precipitation, ${ }^{[2]}$ hard template method, ${ }^{[13]}$ and sol-gel technique, ${ }^{[14,15]}$ etc. Nevertheless, the process of co-precipitation is complicated and the hard template method requires the expensive ordered mesoporous structures. The sol-gel method has attracted more attention owing to the advantages of low reaction temperature and simple operation. ${ }^{16,17]}$ Kang et al. ${ }^{[18]}$ have synthesized $\mathrm{CuCe}_{0.75} \mathrm{Zr}_{0.25} \mathrm{O}_{x}$ catalysts by sol-gel method with oxalate precursor, and the temperature for the complete degradation of toluene is $260{ }^{\circ} \mathrm{C}$. Among the precursors ${ }^{[18-20]}$ used in sol-gel method, green bio-based materials have attracted extensive attentions for preparation of catalysts.

A rich variety of biological materials have been used in the sol-gel method, such as plant leaves, ${ }^{[17]}$ eggshell membranes ${ }^{[14]}$ and bacterial cellulose, ${ }^{[21]}$ etc. Bacterial cellulose $(B C)$ originated from some microorganisms, is a cheap and green bio-based material with rich hydroxyl functional groups, ${ }^{[21]}$ and it has gradually become a hot research topic in the synthesis of catalyst. BC possesses ultrafine three-dimension network structure and unique properties including high crystallinity, good tensile strength, and mouldability. The abundant hydroxyl 
groups and three-dimension nanofibers network not only provide nucleation sites for metal oxide particles but also represent high surface area for contacting more metal ions. Zhang et al. ${ }^{[22]}$ synthesized the mesoporous titania networks with larger crystallinity and accessible surface areas by using BC membranes as natural bio-templates, which significantly improved photocatalytic activity compared with the microfiber titania networks. Yang et al. ${ }^{[23]}$ found that $\mathrm{La}_{2} \mathrm{CuO}_{4}$ nanocrystals synthesized based on $\mathrm{BC}$ nanofibers templates exhibited excellent catalytic performance for methanol steam reforming, attributing to the unique morphology and larger specific area. However, most of the researches were concentrated on the modification of $\mathrm{BC}$, which is not only cumbersome, but also leads to a waste of reagents. In particular, there is a certain content of sugar in BC, which may influence the structure and property of catalyst and consequently influence the catalytic activity. Nevertheless, the interactions between the sugar in $\mathrm{BC}$ and catalyst properties are still not clear.

In this study, BC was directly used as the biological base material without modification to synthesis a series of $\mathrm{CuCe}_{0.75} \mathrm{Zr}_{0.25} \mathrm{O}_{\mathrm{x}}$ by a simple sol-gel method. The interaction between the sugar in
$\mathrm{BC}$ and catalyst properties were explored for the first time, by adjusting the content of sugar in the commercial BC and using different solvent species. We found that the sugar in BC played an important role in the catalyst properties and the catalytic activity, and the research results obtained will be beneficial to the optimization of preparation methods for $\mathrm{Cu}-\mathrm{Ce}-\mathrm{Zr}$ catalyst. Furthermore, based on the in situ DRIFT results, the reaction pathways of the toluene oxidation over $\mathrm{CuCe}_{0.75} \mathrm{Zr}_{0.25} \mathrm{O}_{\mathrm{x}}$ catalysts were discussed.

\section{Results and discussion}

\section{Synthesis mechanism of catalysts The roles of $B C$ in different solvent}

Solvent selection and graft copolymerization are the crucial factors for the synthesis of $\mathrm{CuCe}_{0.75} \mathrm{Zr}_{0.25} \mathrm{O}_{x}$ catalysts based on $\mathrm{BC}$ by using the sol-gel method. $B C$ plays different roles in aqueous and non-aqueous solvents, as shown in Figure 1 and Figure 2, respectively.

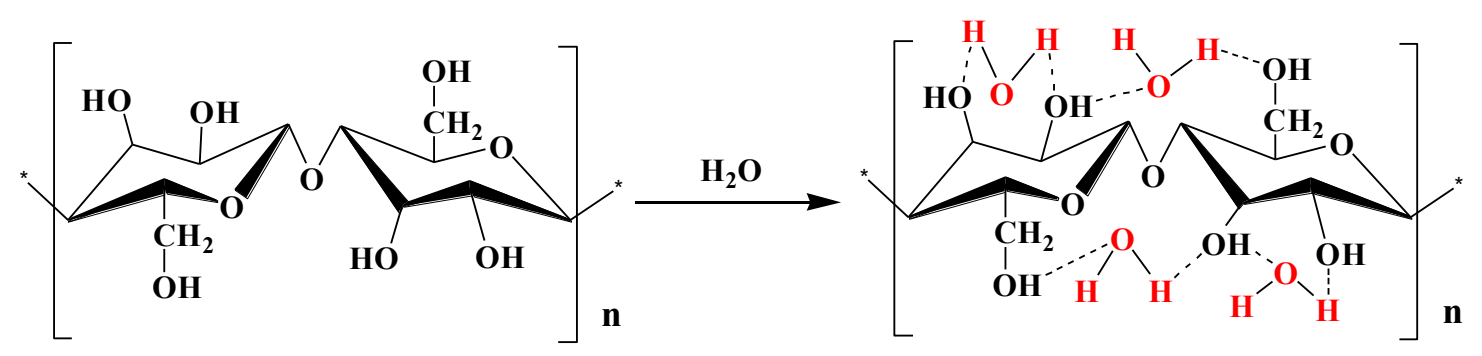

Figure 1. Interaction of $-\mathrm{OH}$ groups of bacterial cellulose in water-ge
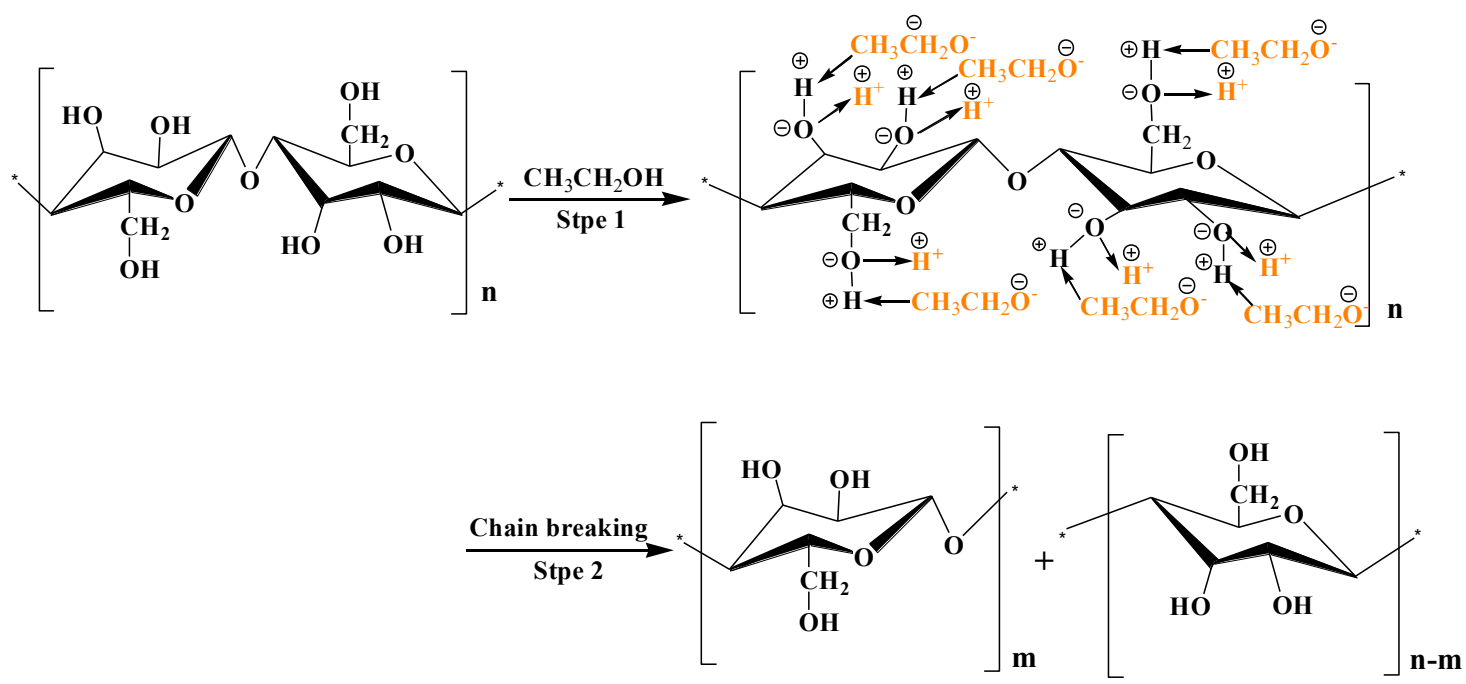

Figure 2. Roles of electron donor-acceptor (EDA) of ethanol-gel during the catalyst preparation process

In water-gel, $\mathrm{H}_{2} \mathrm{O}$ molecules interact with $-\mathrm{OH}$ groups of bacterial cellulose through hydrogen bonds (Figure 1) to form a complex compound, maintaining the $3 \mathrm{D}$ porous network structure of $\mathrm{BC}$. 
Simultaneously, the interaction between $\mathrm{H}_{2} \mathrm{O}$ and $-\mathrm{OH}$ forms steric hindrance, which undoubtedly prevents the reaction of active metal $(\mathrm{Cu}$ and $\mathrm{Ce})$ with $-\mathrm{OH}$. It is not conducive to the dispersion of active metal and eventually leads to agglomeration of metal ions, which is testified by the following XRD data.

Unlike the water-gel, in the presence of $\mathrm{BC}$, the role of ethanol is to provide an electron donor-acceptor $\left(\mathrm{C}_{2} \mathrm{H}_{5} \mathrm{O}^{-}-\mathrm{H}^{+}\right.$: EDA $)$during the catalyst synthesis process (Figure 2). The electron donor center $\left(\mathrm{C}_{2} \mathrm{H}_{5} \mathrm{O}^{-}\right)$and acceptor center $\left(\mathrm{H}^{+}\right)$in ethanol-gel can easily connect with hydrogen and oxygen atoms in the hydroxyl groups $(-\mathrm{OH})$ of $\mathrm{BC}$, respectively (Step 1 in Figure 2). Consequently, the quantity of electric charge of hydroxyl groups $(-\mathrm{OH})$ increases until the main chain of $\mathrm{BC}$ is breaking into small molecule polymers (Step 2 in Figure 2), and leads to decreasing the degree of polymerization. The small molecule polymers provide the higher surface area which exposes more active sites for the active metal.

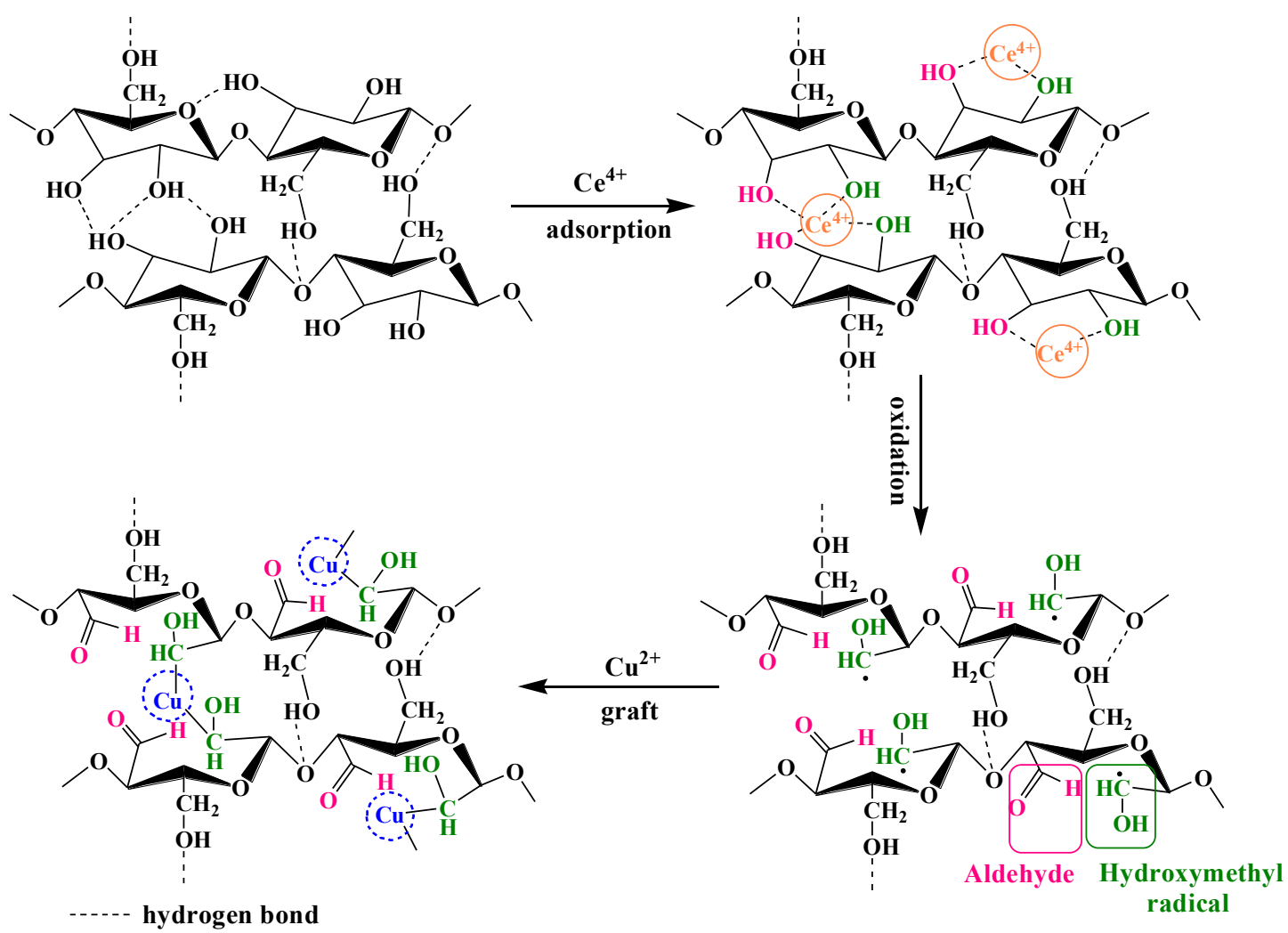

Figure 3. Schematic illustration for graft copolymerization process between $\mathrm{BC}$ and $\mathrm{Ce}^{4+}$ and $\mathrm{Cu}^{2+}$

Graft copolymerization is the addition of another monomer to the main chain of polymer, which is induced by the radical-initiated grafting. ${ }^{[2,25]}$ No matter in water-gel or ethanol-gel, the graft copolymerization between $\mathrm{BC}$ and active metal ions $\left(\mathrm{Ce}^{4+}, \mathrm{Cu}^{2+}\right)$ is the same process (Figure 3). Firstly, $\mathrm{Ce}^{4+}$ is connected to $-\mathrm{OH}$ of $\mathrm{C}_{2}$ and $\mathrm{C}_{3}$ of $\mathrm{BC}$ by hydrogen-bond interaction. Secondly, the $\mathrm{C}_{2}-\mathrm{OH}$ and $\mathrm{C}_{3}-\mathrm{OH}$ of $\mathrm{BC}$ is oxidized by $\mathrm{Ce}^{4+}$ to produce hydroxymethyl radical $(\cdot \mathrm{CH}-\mathrm{OH})$ and aldehyde $(-\mathrm{CHO})$ through the electron transfer process during the sol-gel process. ${ }^{[26]}$ Finally, hydroxymethyl radical $(\cdot \mathrm{CH}-\mathrm{OH})$ can initiate $\mathrm{Cu}^{2+}$ graft by sharing electron pair effect. ${ }^{[27]}$

The roles of sugar in BC during catalyst preparation
The sugar with the content of $15 \%$ is an important part in the commercial BC, which probably influences the catalyst properties. Therefore, TG/DTG analyses of different types of BC were conducted and the sugar from the original solution of commercial BC were investigated, and the corresponding curves are shown in Figure 4. As shown in Figure $4(\mathrm{~A})$, the thermal decomposition results in a weight loss of $\mathrm{BC}$ with sugar at about $200 \sim 300{ }^{\circ} \mathrm{C}$, and the weight loss is approximately $22.3 \%$ with the corresponding weight loss rate of $5.0{ }^{\circ} \mathrm{C} / \mathrm{min}$ at the temperature of $223^{\circ} \mathrm{C}$, which is mainly ascribed to the partial decomposition of sugar, as shown in Figure $4(\mathrm{C})$. With the temperature increasing from 300 to $550{ }^{\circ} \mathrm{C}$, a maximum weight loss $(97 \%)$ appears at about $434{ }^{\circ} \mathrm{C}$ with the weight loss rate of $30.4{ }^{\circ} \mathrm{C} / \mathrm{min}$, which can be explained by the complete decomposition of $\mathrm{BC}$ with sugar. However, the maximum weight loss $(98 \%)$ of $B C$ 
without sugar is $318{ }^{\circ} \mathrm{C}$, which is due to its decomposition. ${ }^{[28]}$ Such phenomenon probably results from the presence of sugar in $B C$, which effectively raises the thermal decomposition temperature of $\mathrm{BC}$ (from $318{ }^{\circ} \mathrm{C}$ to $434{ }^{\circ} \mathrm{C}$ ). The results further prove that the temperature of catalyst calcination at $450{ }^{\circ} \mathrm{C}$ in this study is appropriate. On the one hand, $450{ }^{\circ} \mathrm{C}$ is high enough for the complete decomposition of BC for catalysts synthesized by using $B C$ with and without sugar. On the other hand, the thermal decomposition of $\mathrm{BC}$ with sugar occurs almost simultaneously with the crystallization of catalyst during calcination process. Consequently, it prevents the agglomeration of metal particles during the crystallization process and facilitates the formation of the small metal particles, which was supported by the results of XRD.
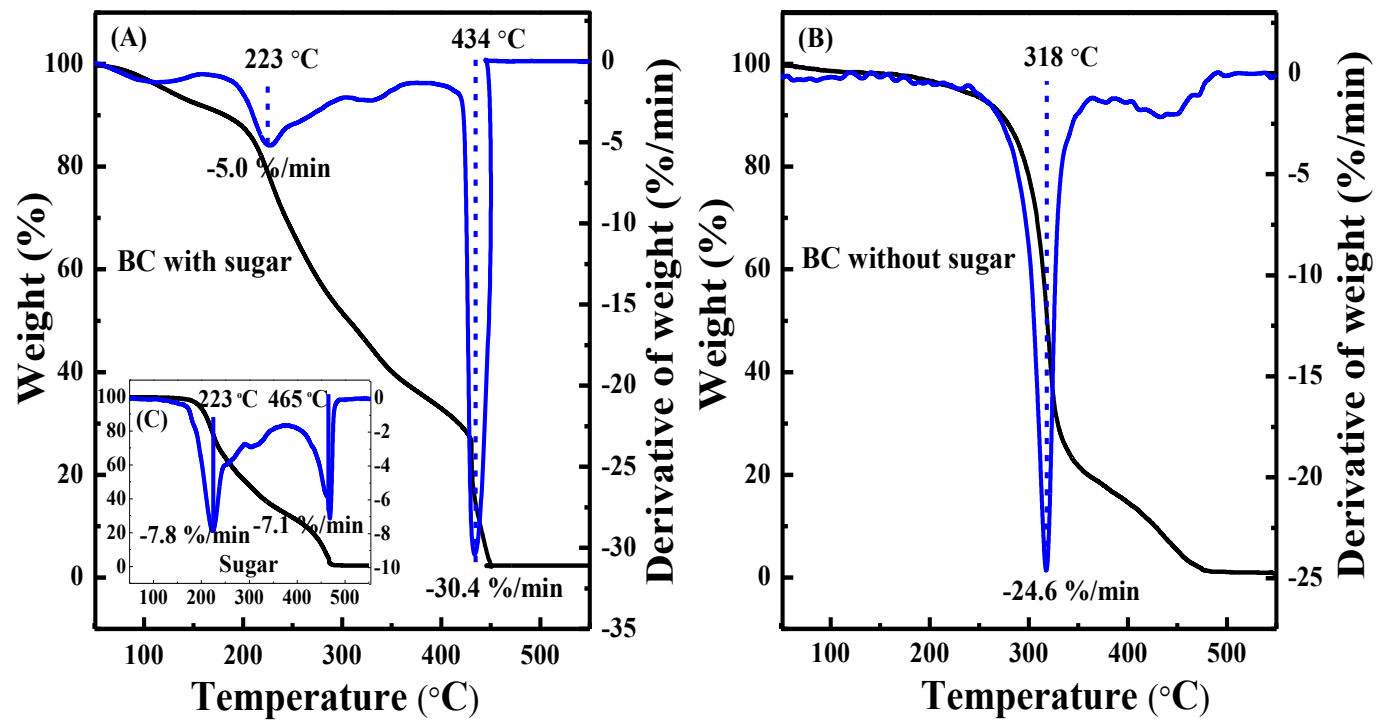

Figure 4. TG/DTG curves of BC with sugar (A), BC without sugar (B) and sugar (C)

Characterizations of catalysts

Crystal structure and textural property

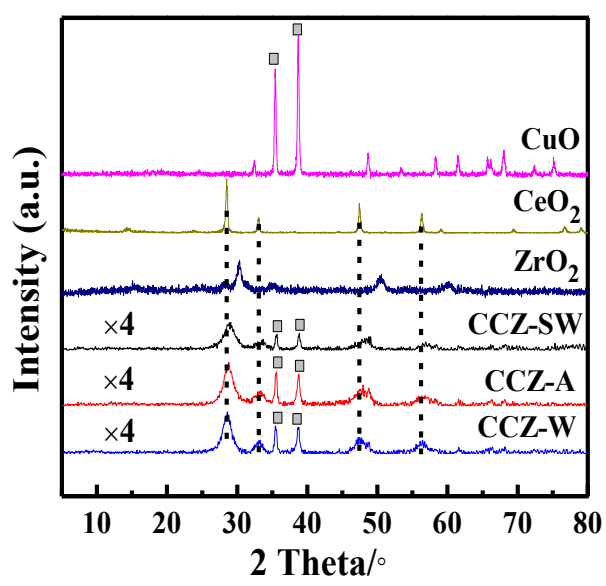

Figure 5. XRD spectra of $\mathrm{CuCe}_{0.75} \mathrm{Zr}_{0.25} \mathrm{O}_{x}$ catalysts

The XRD patterns of $\mathrm{CuCe}_{0.75} \mathrm{Zr}_{0.25} \mathrm{O}_{x}$ catalysts and the crystalline size of $\mathrm{CeO}, \mathrm{CuO}$ in the catalysts are depicted in Figure 5 and Table 1, respectively. All the catalysts show the obvious diffraction peaks of $\mathrm{CeO}_{2}$ fluorite structure at $2 \theta=28.4^{\circ}, 33.1^{\circ}, 47.5^{\circ}$ and $56.3^{\circ}$, which are consistent with the (111), (200),
(220) and (311) crystal structure planes, respectively. Diffraction peaks observed at $2 \theta=35.4^{\circ}$ and $38.8^{\circ}$ represent the crystal structure of $\mathrm{CuO}(-111)$ and $\mathrm{CuO}$ (111). Compared with pure $\mathrm{CeO}_{2}$, the diffraction peaks of the catalysts are weaker and broader, showing that $\mathrm{Cu}^{2+}(0.072 \mathrm{~nm})$ and $\mathrm{Zr}^{4+}(0.084 \mathrm{~nm})$ are incorporated into the lattice of $\mathrm{CeO}_{2}$, forming $\mathrm{Cu}-\mathrm{Ce}-\mathrm{Zr}$ solid solution. ${ }^{29,30]}$ No $\mathrm{ZrO}_{2}$ diffraction peaks contributed to metal oxides are observed, indicating that zirconium species are homogeneously dispersed in the catalysts.

Table 1. Crystalline size of $\mathrm{CeO}_{2}, \mathrm{CuO}$ in $\mathrm{CuCe}_{0.75} \mathrm{Zr}_{0.25} \mathrm{O}_{x}$ catalysts

\begin{tabular}{ccc}
\hline \multirow{2}{*}{ Samples } & \multicolumn{2}{c}{ Crystalline size $(\mathrm{nm})$} \\
\cline { 2 - 3 } & $\mathrm{CeO}_{2}$ & $\mathrm{CuO}$ \\
\hline CCZ-SW & 4.1 & 6.9 \\
CCZ-A & 16.3 & 8.5 \\
CCZ-W & 18.4 & 10.1 \\
\hline
\end{tabular}

From Table 1, it is obvious that the crystal size of active metals in CCZ-W is the largest. Due to the formation of steric hindrance, some $\mathrm{Cu}^{2+}$ and $\mathrm{Ce}^{4+}$ can't be dispersed on the network structure of BC, which eventually leads to the higher degree of crystallinity and larger crystal size of the corresponding active metals crystal phase in CCZ-W 
than that in CCZ-A. Compared with CCZ-A and CCZ-W, CCZ-SW exhibits a lower degree of crystallinity and a smaller particle size as the BC is enriched with sugar. This result can be attributed to the fact that the presence of sugar in BC prevents the crystallization and agglomeration of active metals during the catalyst calcination process, which allows the formation of smaller active metal oxide crystallites.

The $\mathrm{N}_{2}$ adsorption/desorption isotherms and pore size distribution of the different $\mathrm{CuCe}_{0.75} \mathrm{Zr}_{0.25} \mathrm{O}_{\mathrm{x}}$ catalysts are shown in Figure 6, and the textural properties of the catalysts are summarized in Table 2 . All the catalysts exhibit IV shape isotherms with a similar H4-type hysteresis loops at the relative pressure range of $0.45 \sim 1.0$, which conforms the formation of the abundant mesoporous structure in the catalysts. ${ }^{[31]}$ The hysteresis loop at middle relative pressure $\left(P / P_{0}=0.45 \sim 0.8\right)$ is mainly ascribed to the capillary condensation of framework-confined mesopores, while the loop at $\mathrm{P} / \mathrm{P}_{0}=0.8 \sim 1.0$ indicates the presence of $\mathrm{a}$ significant amount of textural pores, contributing to the filling of interparticle spaces. ${ }^{[32,33]}$

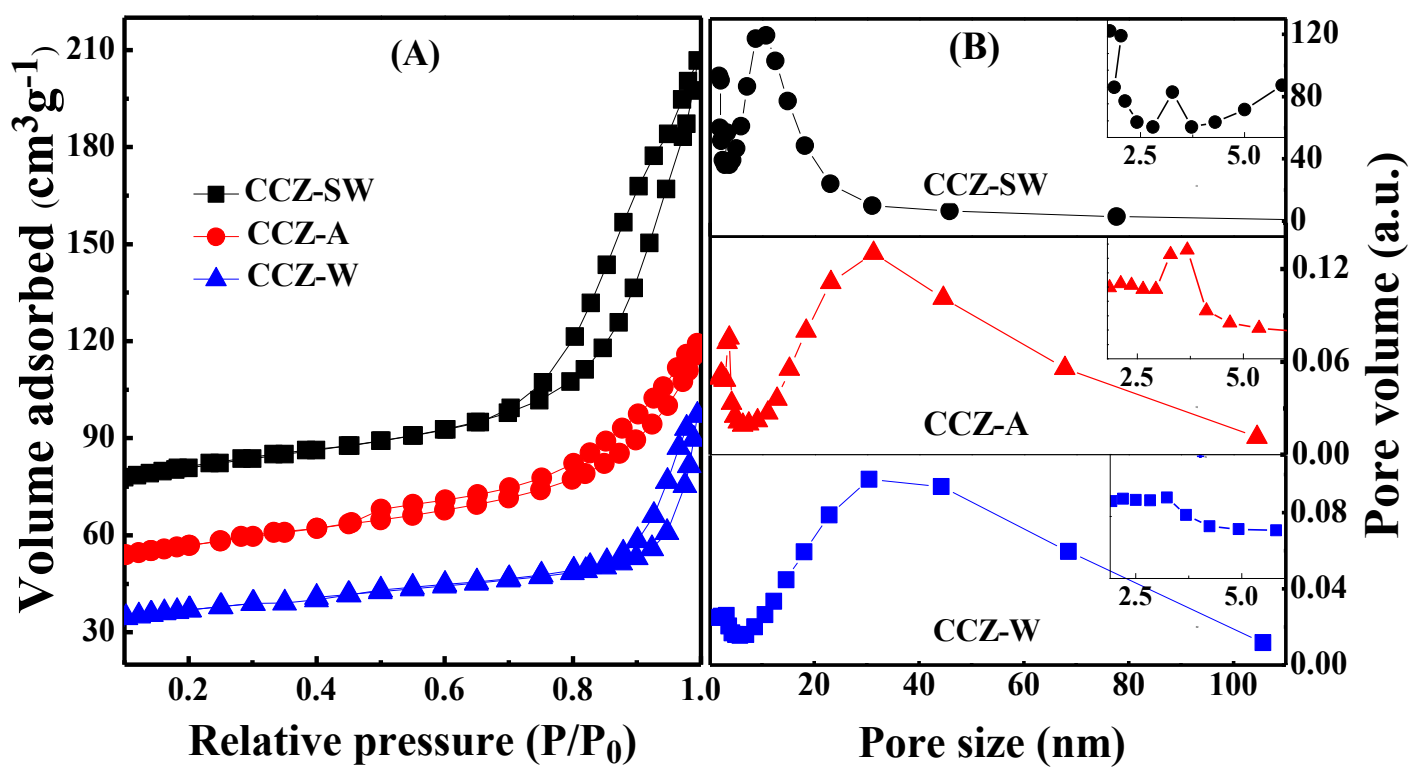

Figure 6. $\mathrm{N}_{2}$ adsorption/desorption isotherms (A) and pore size distributions (B) of different $\mathrm{CuCe}_{0.75} \mathrm{Zr}_{0.25} \mathrm{O}_{\times}$catalysts

Furthermore, it can be seen from Figure 6 (B) that the tendency of the pore size distribution of CCZ-A is similar to that of CCZ-W, indicating the presence of the mesoporous structure in the catalysts.

Table 2. Textural properties of $\mathrm{CuCe}_{0.75} \mathrm{Zr}_{0.25} \mathrm{O}_{x}$ catalysts

\begin{tabular}{cccl}
\hline Samples & $S_{\text {BET }}\left(\mathrm{m}^{2} \cdot \mathrm{g}^{-1}\right)$ & $V_{\mathrm{p}}\left(\mathrm{cm}^{-3} \cdot \mathrm{g}^{-1}\right)$ & $D_{\mathrm{p}}(\mathrm{nm})$ \\
\hline CCZ-SW & 59 & 0.22 & 11.04 \\
CCZ-A & 45 & 0.11 & 9.32 \\
CCZ-W & 28 & 0.09 & 13.03 \\
\hline
\end{tabular}

However, the CCZ-A shows higher specific surface area $\left(S_{\mathrm{BET}}\right.$ ) than CCZ-W (Table 2), probably owing to the breaking of $\mathrm{BC}$ into small molecule polymers and providing a high surface exposure of active sites for active metal. For CCZ-SW, the pore size distribution exhibits the combination of micropores smaller than $2 \mathrm{~nm}$ and mesopores at about $10 \mathrm{~nm}$, suggesting the formation of the hierarchically porous structure. With the presence of sugar in $\mathrm{BC}$, the $S_{\mathrm{BET}}$ of CCZ-W increases from 28 $\mathrm{m}^{2} \cdot \mathrm{g}^{-1}$ to $59 \mathrm{~m}^{2} \cdot \mathrm{g}^{-1}$ of CCZ-SW, owing to the formation of small metal oxide crystal particles (see $\mathrm{XRD}$ results).

\section{Oxygen vacancy concentration and oxygen species}

The Raman spectra and oxygen vacancy concentration of $\mathrm{CuCe}_{0.75} \mathrm{Zr}_{0.25} \mathrm{O}_{x}$ catalysts together with pure $\mathrm{CeO}_{2}$ for comparison are shown in Figure 7. Pure $\mathrm{CeO}_{2}$ exhibits four distinct peaks at 281,460 , 602 and $1178 \mathrm{~cm}^{-1}$. The peak at $281 \mathrm{~cm}^{-1}$ attributes to the rearrangement of the oxygen atoms from $\mathrm{CeO}_{2}$ ideal fluorite lattice positions. ${ }^{[34]}$ The strong peak at $460 \mathrm{~cm}^{-1}$ is the $F_{2 \mathrm{~g}}$ vibration mode of the cubic fluorite-structure phase of $\mathrm{CeO}_{2} \cdot{ }^{[35]}$ And the two peaks at 602 and $1178 \mathrm{~cm}^{-1}$ are ascribed to the oxygen vacancies $\left(O_{v}\right)$ in $\mathrm{CeO}_{2}$ and the primary $A_{1 g}$ asymmetry of $\mathrm{CeO}_{2}$, respectively. ${ }^{[36,37]}$

As shown in Figure $7(B)$, the values of oxygen vacancy concentration $\left(O_{v} / F_{2 g}\right)$, calculated by the intensity ratio of the bands at 602 and $460 \mathrm{~cm}^{-1}$, for all the catalysts are significantly higher than that of 
pure $\mathrm{CeO}_{2}$, resulting in more oxygen vacancies and indicating that the lattice distortion of $\mathrm{CeO}_{2}$ caused by the incorporation of $\mathrm{Cu}^{2+}$ and $\mathrm{Zr}^{4+}$ into the $\mathrm{CeO}_{2}$ lattice. In addition, the $O_{v} / F_{2 g}$ value of CCZ-A (0.649) is dramatically higher than that of CCZ-W (0.375). Combined with the synthesis mechanism of catalysts, $\mathrm{Cu}^{2+}$ and $\mathrm{Zr}^{4+}$ are more easily doped into the ceria lattice, leading to the formation of more oxygen vacancies in CCZ-A than that in CCZ-W. It is obvious that CCZ-SW possesses the highest concentration of oxygen vacancy (0.68) that is favorable for accelerating the surface electron transfer and promoting the catalytic oxidation reaction.

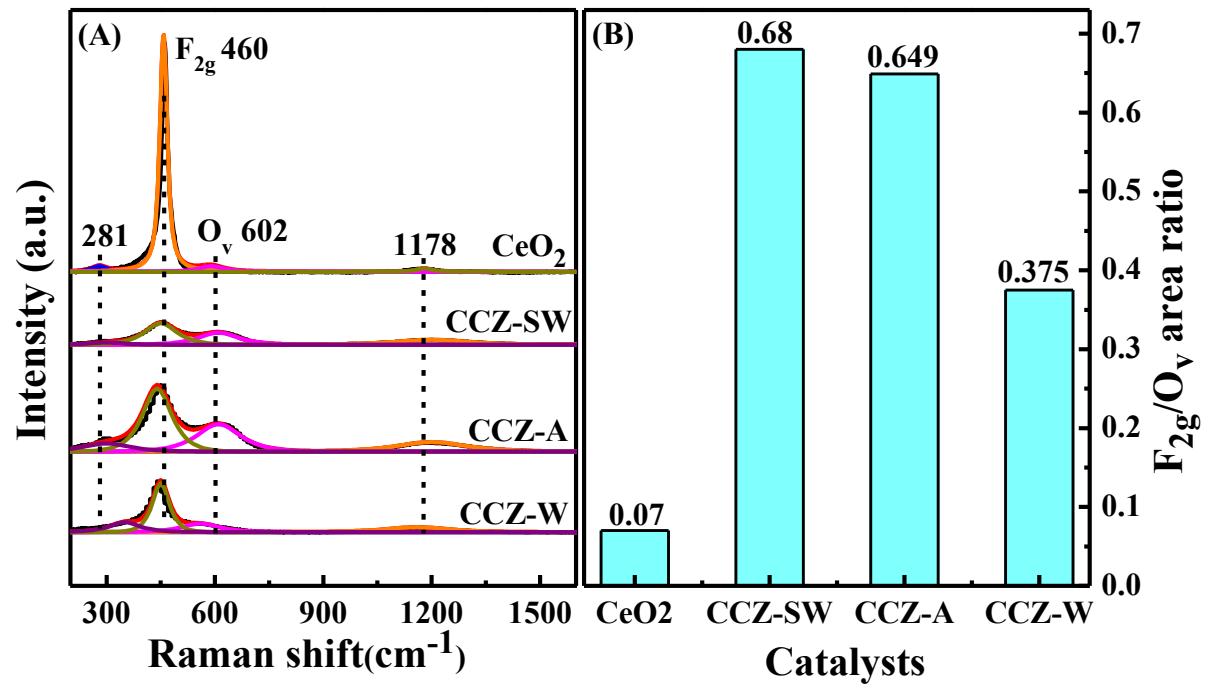

Figure 7. Raman spectra (A) and oxygen vacancy concentration (B) of $\mathrm{CuCe}_{0.75} \mathrm{Zr}_{0.25} \mathrm{O}_{x}$ catalysts

$\mathrm{O}_{2}$-TPD patterns of the catalysts and the corresponding amount of $\mathrm{O}_{2}$ desorption are illustrated in Figure 8 and Table 3 . The $\mathrm{O}_{2}$-TPD spectra of all the catalysts can be divided into three peaks. $\alpha$ peak $\left(400 \sim 600{ }^{\circ} \mathrm{C}\right)$ represents the desorption peaks of the chemisorption of surface-active oxygen species $\left(\mathrm{O}_{2}{ }^{-} / \mathrm{O}^{-}\right)$. $\quad \beta$ peak $\left(800 \sim 900{ }^{\circ} \mathrm{C}\right)$ and $\gamma$ peak $\left(900 \sim 980{ }^{\circ} \mathrm{C}\right)$ are ascribed to the desorption of the surface lattice oxygen and bulk lattice oxygen, respectively. ${ }^{[38]}$

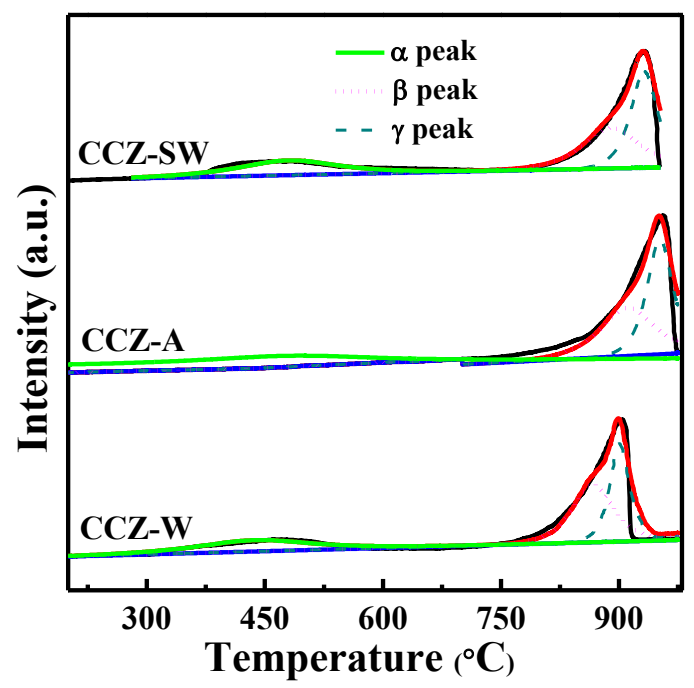

Figure 8. $\mathrm{O}_{2}$-TPD profiles of $\mathrm{CuCe}_{0.75} \mathrm{Zr}_{0.25} \mathrm{O}_{\times}$catalysts

Table 3. $\mathrm{O}_{2}$ desorption of the $\mathrm{CuCe}_{0.75} \mathrm{Zr}_{0.25} \mathrm{O}_{x}$ catalysts

\begin{tabular}{ccccc}
\hline \multirow{2}{*}{ Samples } & \multicolumn{4}{c}{$\mathrm{O}_{2}$ desorption $\left(\mu \mathrm{mol} \cdot \mathrm{g}^{-1}\right)$} \\
\cline { 2 - 5 } & $\alpha$ peak & $\beta$ peak & $\gamma$ peak & Total \\
\hline CCZ-SW & 2.9 & 3.7 & 4.0 & 10.6 \\
CCZ-A & 2.0 & 3.9 & 3.5 & 9.4 \\
CCZ-W & 2.0 & 3.6 & 3.0 & 8.6 \\
\hline
\end{tabular}

From Table 3 , it is remarkable that the total amount of $\mathrm{O}_{2}$ desorption for CCZ-SW are higher than that for CCZ-A and CCZ-W, suggesting a relatively higher mobility of oxygen species for the stronger synergy among Cu-Ce-Zr solid solution. In addition, the larger accessible surface area of CCZ-SW and the stronger synergy between $\mathrm{CuO}$ and $\mathrm{CeO}_{2}$, accelerating the electron transfer between $\mathrm{Ce}^{4+} / \mathrm{Ce}^{3+}$ and $\mathrm{Cu}^{2+} / \mathrm{Cu}^{+}$, possibly increase the amount of chemical adsorption oxygen and facilitate the migration of lattice oxygen species.

\section{Temperature-programmed reduction by hydrogen}

$\mathrm{H}_{2}$-TPR profiles of the catalysts are shown in Figure 9 , and the corresponding $\mathrm{H}_{2}$ consumptions are listed in Table 4. It is obvious that the reduction peaks of the catalysts exhibit three peaks at $100 \sim 350^{\circ} \mathrm{C}$, which are attributed to the reduction of the $\mathrm{Cu}-\mathrm{Ce}$ soild solution ( $\alpha$ peak), dispersed $\mathrm{CuO}(\beta$ peak) and crystallized $\mathrm{CuO}$ ( $\gamma$ peak) over the 
$\mathrm{CuCe}_{0.75} \mathrm{Zr}_{0.25} \mathrm{O}_{\mathrm{x}}$ catalyst. According to our previous research, ${ }^{[39]}$ the reducibility of copper species decreases in the following order: $\mathrm{Cu}-\mathrm{Ce}$ solid solution $>$ dispersed $\mathrm{CuO}>$ crystallized $\mathrm{CuO}$.

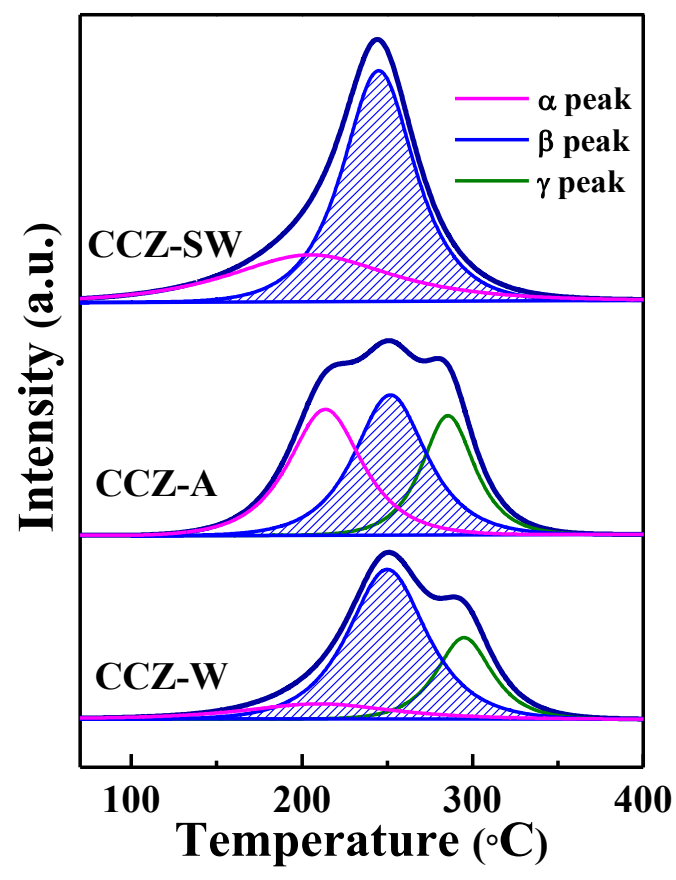

Figure 9. $\mathrm{H}_{2}$-TPR profiles of $\mathrm{CuCe}_{0.75} \mathrm{Zr}_{0.25} \mathrm{O}_{x}$ catalysts

Table 4. $\mathrm{H}_{2}$ consumption of the $\mathrm{CuCe}_{0.75} \mathrm{Zr}_{0.25} \mathrm{O}_{x}$ catalysts

\begin{tabular}{ccccc}
\hline \multirow{2}{*}{ Samples } & \multicolumn{4}{c}{$\mathrm{H}_{2}$ consumption $\left(\mu \mathrm{mol} \cdot \mathrm{g}^{-1}\right)$} \\
\cline { 2 - 5 } & $\alpha$ peak & $\beta$ peak & $\gamma$ peak & total \\
\hline CCZ-SW & 63.0 & 97.6 & - & 160.6 \\
CCZ-A & 45.5 & 70.8 & 42.8 & 159.1 \\
CCZ-W & 29.8 & 64.3 & 39.1 & 133.2 \\
\hline
\end{tabular}

As listed in Table 4, the total $\mathrm{H}_{2}$ consumption amounts of $\alpha$ and $\beta$ peaks (160.6 $\mu \mathrm{mol} \cdot \mathrm{g}^{-1}$ ) for CCZ-SW is much higher than that of CCZ-A and CCZ-W, suggesting the excellent low-temperature reducibility of CCZ-SW. The results also demonstrate that the existence of sugar in $\mathrm{BC}$ promotes the reducibility of copper species ( $\mathrm{Cu}-\mathrm{Ce}$ solid solution and dispersed $\mathrm{CuO}$ ). It can be attributed to the larger specific surface area of $\mathrm{BC}$, not only promoting the dispersion of $\mathrm{CuO}$, but also facilitating the highly dispersed copper oxide species, that strongly interacts with $\mathrm{CeO}_{2}$ to form $\mathrm{Cu}$-Ce solid solution. Therefore, the low-temperature reducibility of the synthesized catalysts decreases in the sequence of CCZ-SW > CCZ-A > CCZ-W.

\section{The application of catalyst in toluene degradation Catalytic activity}

The toluene conversion and $\mathrm{CO}_{2}$ selectivity over catalysts are shown in Figure 10. The temperature of complete degradation toluene over CCZ-SW, CCZ-A and CCZ-W is $205{ }^{\circ} \mathrm{C}, 215{ }^{\circ} \mathrm{C}$ and $240{ }^{\circ} \mathrm{C}$, respectively. Hence, the catalytic activity order of the catalysts is CCZ-SW > CCZ-A > CCZ-W. The CCZ-W exhibits the highest toluene total conversion temperature $\left(240^{\circ} \mathrm{C}\right)$, which are much higher than that of CCZ-A $\left(215^{\circ} \mathrm{C}\right)$. Combined with the synthesis mechanism of catalysts, the results can be explained by the fact that $\mathrm{BC}$ plays different roles in water-gel and ethanol-gel. Compared with water-gel, BC without sugar in ethanol-gel is more favorable to form small molecule polymers, which provides a higher surface area exposing more nucleation sites for active metal. It is beneficial to the dispersion of metal ions that prevent the crystallization and agglomeration of active metals, eventually leading to the enhancement of catalytic activity of CCZ-A. It is worth noting that CCZ-SW exhibits the optimum catalytic activity for toluene destruction than CCZ-A and $C C Z-W$, indicating that the presence of sugar in BC significantly influences the catalytic performance. The corresponding $T_{10}, T_{50}, T_{90}$ and $T_{100}$ (temperature at $10 \%, 50 \%, 90 \%$ and $100 \%$ toluene conversion, respectively) of CCZ-SW are $170{ }^{\circ} \mathrm{C}, 190^{\circ} \mathrm{C}, 198^{\circ} \mathrm{C}$ and $205^{\circ} \mathrm{C}$, which are $35^{\circ} \mathrm{C}$ lower than those of CCZ-W. The excellent activity of CCZ-SW can be attributed to its larger specific surface area $\left(59 \mathrm{~m}^{2} \cdot \mathrm{g}^{-1}\right)$, the high concentration of oxygen vacancies $(0.68)$ and the superior reducibility $\left(160.6 \mu \mathrm{mol} \cdot \mathrm{g}^{-1}\right)$. The oxygen vacancies accelerate the adsorption and dissociation of oxygen molecules, which provide active centres for the formation of reactive oxygen species that further promote the catalyst activity, and simultaneously improve the diffusion of the lattice oxygen. In addition, the larger specific surface area not only promotes the dispersion of $\mathrm{CuO}$, but also facilitates the highly dispersed copper oxide species, strongly interacting with $\mathrm{CeO}_{2}$ to form $\mathrm{Cu}-\mathrm{Ce}$ solid solution. The synergetic effect between $\mathrm{CuO}$ and $\mathrm{CeO}_{2}$ can weaken the $\mathrm{Cu}-\mathrm{O}$ and $\mathrm{Ce}-\mathrm{O}$ chemical bonds, resulting in producing more reactive oxygen species and providing a facilitated redox process. 


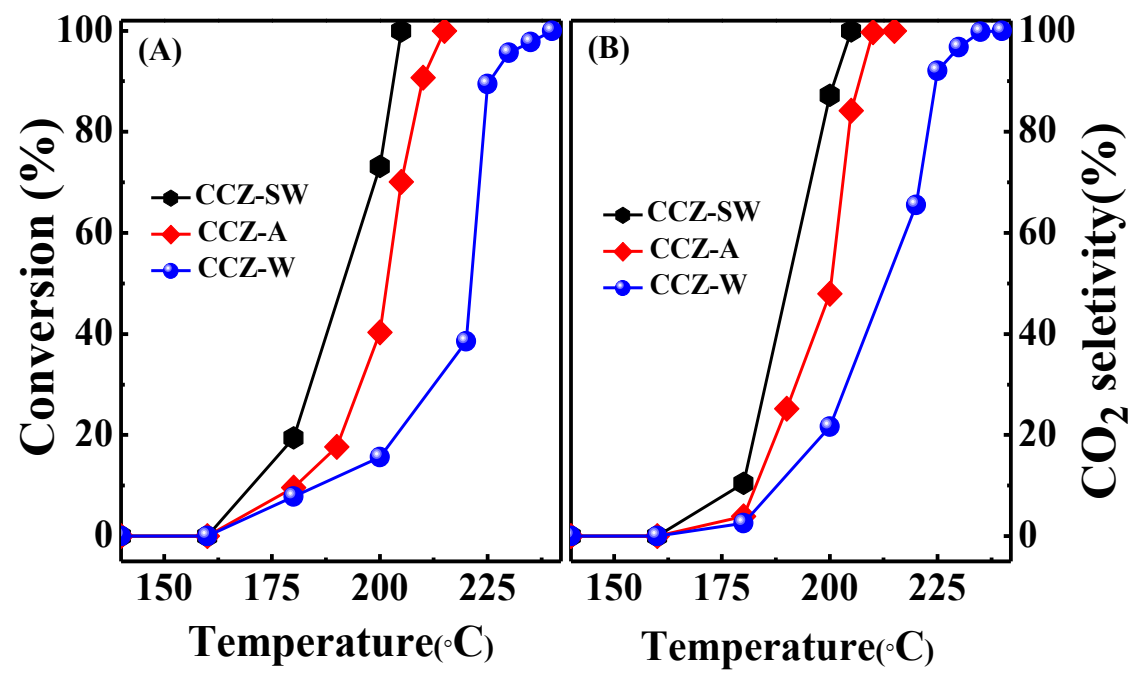

Figure 10. Toluene conversion (A) and $\mathrm{CO}_{2}$ selectivity (B) over $\mathrm{CuCe}_{0.75} \mathrm{Zr}_{0.25} \mathrm{O}_{x}$ catalysts

\section{Mechanism of the catalytic oxidation of toluene}

The in situ DRIFT spectra were obtained to study the reaction pathways of toluene oxidation on CCZ-SW catalyst, and the results are shown in Figure 11. The bands at $3100-2850 \mathrm{~cm}^{-1}$ ascribed to $\mathrm{C}-\mathrm{H}$ stretching of typical aromatic ring are obviously observed and the intensity gradually decreases with the time. The bands at $1620-1370 \mathrm{~cm}^{-1}$ are attributed to the $\mathrm{C}=\mathrm{C}$ stretch of the aromatic rings. Moreover, the bands corresponding to the vibrations of methylene $\left(-\mathrm{CH}_{2}\right)$ rather than methyl $\left(-\mathrm{CH}_{3}\right)$ are detected at 2933 and $2878 \mathrm{~cm}^{-1}$, because the $\mathrm{C}-\mathrm{H}$ stretching vibration of the methyl $\left(-\mathrm{CH}_{3}\right)$ is usually appeared at $2970-2950 \mathrm{~cm}^{-1}$ region. ${ }^{[40-42]}$ The strong bands appeared at 1073 and $1036 \mathrm{~cm}^{-1}$ belongs to the $\mathrm{C}-\mathrm{O}$ vibrations, which are probably caused by the reaction between toluene and CCZ-SW catalyst to form alkoxide species. ${ }^{[43]}$ The results indicate that when toluene is adsorbed on the active sites of CCZ-SW catalyst surface, the first step is the cracking of the $\mathrm{C}-\mathrm{H}$ bonds of methyl group; thus the benzyl species $\left(\mathrm{C}_{6} \mathrm{H}_{5}-\mathrm{CH}_{2}{ }^{*}\right)$ are formed, which are further oxidized into the alkoxide species. The bands at $2739(\mathrm{C}-\mathrm{H}), 1733$ and $1650 \mathrm{~cm}^{-1} \quad(\mathrm{C}=\mathrm{O})$ corresponding to aldehydic species are detected. ${ }^{[41,43]}$ Accordingly, the bands at $1794(\mathrm{C}=\mathrm{O})$, 1555, 1538 (COO) and $1396 \mathrm{~cm}^{-1}(\mathrm{O}-\mathrm{H})$ are associated with the formation of carboxylic acid species. ${ }^{[41]}$ At the temperature of $280{ }^{\circ} \mathrm{C}$, the intensity of the bands attributed to $\mathrm{CO}_{2}\left(2345 \mathrm{~cm}^{-1}\right)$ and $\mathrm{H}_{2} \mathrm{O}\left(3800-3150 \mathrm{~cm}^{-1}\right)$ increases remarkably, while the intensity of alkoxide, aldehydic and carboxylic acid species decreases gradually and even disappears. With the temperature higher than $280{ }^{\circ} \mathrm{C}$, the bands at $1750-1580,1450$ and 1340 $\mathrm{cm}^{-1}$ assigned to $\mathrm{CO}_{3}{ }^{2-}$ appear, which are attributed to the combination of $\mathrm{CO}_{2}$ and $\mathrm{H}_{2} \mathrm{O}$, and the intensity increases with increasing temperature. Therefore, it can be concluded that the alkoxide, aldehydic and carboxylic acid species are identified as the three major types of intermediates before the complete toluene oxidation into $\mathrm{CO}_{2}$ and $\mathrm{H}_{2} \mathrm{O}$.

In this study, the pathway of toluene oxidation over Cu-Ce-Zr catalysts, corresponding to the Mars-van Krevelen mechanism, is shown in Figure 12. In this mechanism, the electronic transfer among the reactants, the intermediate species and the $\mathrm{Cu}-\mathrm{Ce}-\mathrm{Zr}$ catalysts dominates the whole reaction. ${ }^{[37,44]}$ Firstly, the toluene molecule adsorbed at the active sites primarily reacts with the lattice oxygen of metal oxides, leading to the formation of surface oxygen vacancies and three major types of intermediates (alkoxide, aldehydic and carboxylic acid species) which are eventually oxidized to $\mathrm{CO}_{2}$ and $\mathrm{H}_{2} \mathrm{O}$. Then, the oxygen from the gas phase refills the oxygen vacancies immediately to complete the cycle of toluene oxidation reaction. Compared with the other catalysts, the CCZ-SW can provide more lattice oxygen and reactive oxygen species to accelerate the oxidation of toluene molecules, which is supported by the Raman and $\mathrm{O}_{2}$-TPD results. 

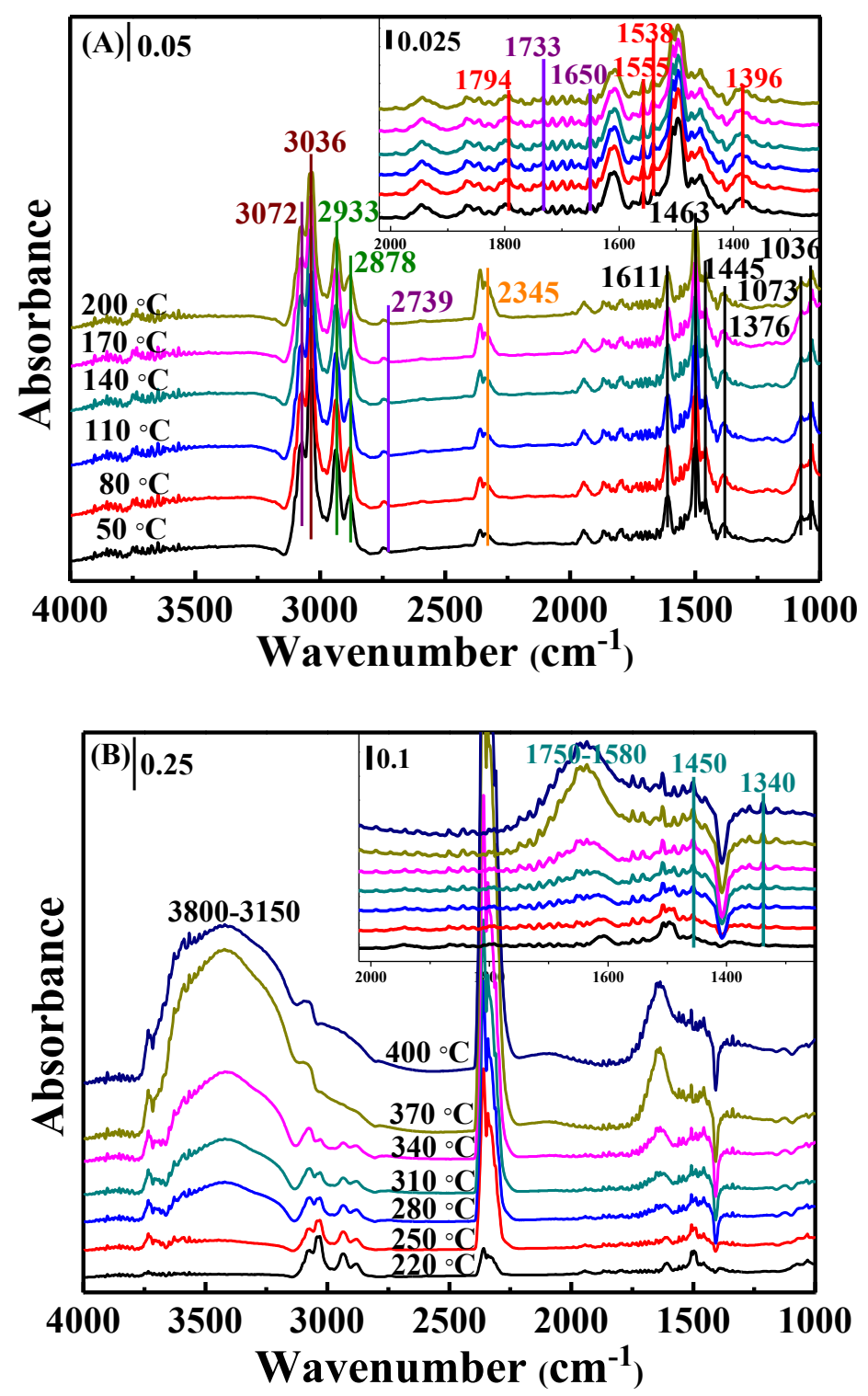

Figure 11. In situ DRIFT spectra for toluene oxidation over CCZ-SW at different temperature 


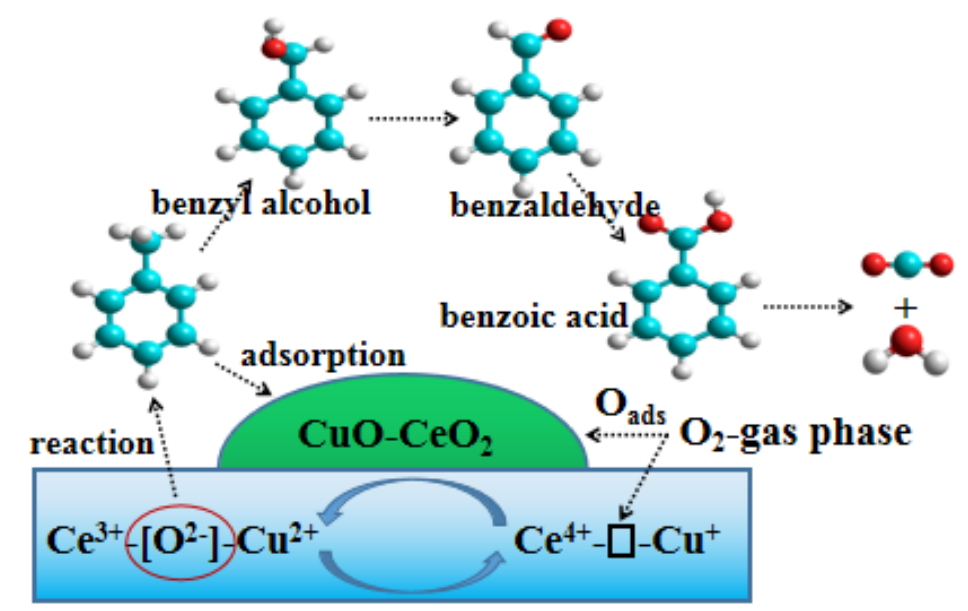

Figure 12. The reaction pathways of toluene oxidation over the $\mathrm{CuCe}_{0.75} \mathrm{Zr}_{0.25} \mathrm{O}_{\mathrm{x}}$ catalysts

\section{Conclusions}

A series of $\mathrm{CuCe}_{0.75} \mathrm{Zr}_{0.25} \mathrm{O}_{x}$ catalysts were prepared by sol-gel method using environmental-friendly $\mathrm{BC}$. The relationships between the catalyst properties and catalytic behaviors of the $\mathrm{CuCe}_{0.75} \mathrm{Zr}_{0.25} \mathrm{O}_{\mathrm{x}}$ catalysts were studied, and the main conclusions are as follows.

(1) BC plays different roles in water-gel and ethanol-gel during the process of catalysts synthesis. However, the graft copolymerization between BC and active metal $\left(\mathrm{Ce}^{4+}, \mathrm{Cu}^{2+}\right)$ is the same process no matter in water-gel or ethanol-gel. Moreover, the existence of sugar in $\mathrm{BC}$ can hinder the agglomeration of metal ions during the calcination process, which is beneficial to the enhancement of catalytic activity.

(2) The catalytic activity for toluene oxidation decreases in the order of CCZ-SW $>$ CCZ-A $>$ CCZ-W, and the corresponding $T_{100}$ are $205^{\circ} \mathrm{C}, 215$ ${ }^{\circ} \mathrm{C}$ and $240{ }^{\circ} \mathrm{C}$, respectively. The excellent catalytic activity of CCZ-SW can be attributed to the larger specific surface area, the more oxygen vacancies and superior reducibility, which accelerate the electron transfer between $\mathrm{Ce}^{4+} / \mathrm{Ce}^{3+}$ and $\mathrm{Cu}^{2+} / \mathrm{Cu}^{+}$, further increasing the amount of chemical adsorption oxygen and facilitating the migration of lattice oxygen species.

(3) The pathway of toluene oxidation over CCZ-SW catalyst conforms to the Mars-van Krevelen mechanism, in which adsorbed toluene reacting with lattice oxygen can be completely degraded into $\mathrm{CO}_{2}$ and $\mathrm{H}_{2} \mathrm{O}$ through the intermediates of alkoxide, aldehydic and carboxylic acid species.

\section{Supporting Information Summary}

Experimental section including Catalyst preparation, Catalyst characterizations and Catalytic activity test have been reported in Supporting Information

\section{Acknowledgments}

We gratefully thank the financial support from the Postdoctoral Science Foundation of China (No. 2017M623284), and the technical support from Research Centre of Modern Analytic Technology from Tianjin University of Science \& Technology, Tianjin, 300457, China.

\section{Conflict of Interest}

The authors declare no conflict of interest

Keywords: Bacterial cellulose - Sol-gel • Toluene oxidation • Graft copolymerization • Reaction mechanism

[1] M. Konsolakis, S.A. Carabineiro, P.B. Tavares, J.L. Figueiredo, J Hazard Mater. 2013, 261, 512-521.

[2] C. He, Y. Yu, Y. Lin, N. Qiao, J. Li, Q. Shen, W. Yu, J. Chen, Z. Hao, Appl Catal B. 2014, 147, 156-166.

[3] J. Sun, L. Bo, L. Yang, X. Liang, X. Hu, Rsc Adv. 2014, 4, 14385-14391.

[4] Z. Zhang, Z. Jiang, W. Shangguan, Catal Today. 2016, 264, 270-278.

[5] P. Yang, S. Yang, Z. Shi, Z. Meng, R. Zhou, Appl Catal B. 2015, 162, 227-235.

[6] S. Li, Q. Hao, R. Zhao, D. Liu, H. Duan, B. Dou, Chem Eng J. 2016, 285, 536-543.

[7] H. Lu, X. Kong, H. Huang, Y. Zhou, Y. Chen, J Environ Sci-China. 2015, 32, 102-107.

[8] F. Bin, C. Song, G. Lv, J. Song, S. Wu, X. Li, App/ Catal B. 2014, s150-151, 532-543.

[9] C. He, B.T. Xu, J.W. Shi, N.L. Qiao, Z.P. Hao, J.L. Zhao, Fuel Process Technol. 2015, 130, 179-187.

[10] P.O. Larsson, A. Andersson, L.R. Wallenberg, S. Bo, J 
Catal. 1996, 163, 279-293.

[11] Q. Huang, X. Xue, R. Zhou, J Mol Catal A-Chem. 2011, 344 74-82.

[12] T.M.C. Hoang, N.K. Rao, L. Lefferts, K. Seshan, Chemcatchem. 2015, 7, 468-478.

[13] D.R. Sellick, A. Aranda, T. García, J.M. López, B. Solsona, A.M. Mastral, D.J. Morgan, A.F. Carley, S.H. Taylor, Appl Catal B-Environ. 2013, 132-133, 98-106

[14] W. Tang, X. Wu, G. Liu, S. Li, D. Li, W. Li, Y. Chen, J Rare Earth. 2015, 33, 62-80.

[15] W. Tang, W. Li, X. Shan, X. Wu, Y. Chen, Mater Lett. 2015 , 140, 95-98.

[16] L.Q. Ye, Y.L. Zhang, C.C. Song, Mater Lett. 2016, 188, 316-318.

[17] R.D. Marcello, H.M.N. Eduardo, L.V. Wander, Ceram Int. 2016, 42, 9488-9495.

[18] R. Kang, X. Wei, H. Li, F. Bin, R. Zhao, Q. Hao, B. Dou, Combust Sci Technol. 2017, 190, 878-892.

[19] G.L. Zhou, H. Lan, T.T. Gao, H.M. Xie, Chem Eng J. 2014, 246, 53-63.

[20] Q.F. Deng, T.Z. Ren, A. Bao, Y. Liu, Z.Y. Yuan, J Ind Eng Chem. 2014, 20, 3303-3312.

[21] S. Liu, W. Yan, X. Cao, Z. Zhou, R. Yang, In J Hydrogen Energ. 2016, 41, 5351-5360.

[22] D. Zhang, L. Qi, Chem Commun. 2005, 21, 2735-2737.

[23] J. Yang, W. Tang, X. Liu, C. Chao, J. Liu, D. Sun, In J Hydrogen Energ. 2013, 38, 10813-10818.

[24] G. Mino, S. Kaizerman, J Polym Sci Pol Chem. 1958, 31, 242-243.

[25] F.E. Okieimen, D.E. Ogbeifun, J Appl Polym Sci. 1996, 59, 981-986.

[26] K.C. Gupta, K. Khandekar, Biomacromolecules. 2003, 4, 758.

[27] E. Bianchi, E. Marsano, L. Ricco, S. Russo, Carbohyd. Polym. 1998, 36, 313-318.

[28] Y.L. Wang, S.N. Zhang, Y.W. Mai, Y.Z. Wan, S.H. Lim, F. He Y. Huang, Nanotech Precis Eng. 2009, 7, 95-101.

[29] Q.F. Deng, T.Z. Ren, A. Bao, Y. Liu, Z.Y. Yuan, J Ind Eng Chem. 2014, 20, 3303-3312.

[30] Q. Zhang, L. Xu, P. Ning, J. Gu, Q. Guan, Appl Surf Sci. 2014, 317, 955-961.

[31] S.L. Chang, J.Y. Lim, W.S. Chi, J.H. Kim, Electrochim Acta. 2015, 173, 139-147.

[32] M.A. Camblor, A. Corma, S. Valencia, Micropor Mesopor Mat. 1998, 25, 59-74.

[33] K. Miyazawa, S. Inagaki, Chem Commun. 2000, 21, 2121-2122.

[34] X. Guo, L. Jing, R. Zhou, Fuel. 2016, 163, 56-64.

[35] T. Tsoncheva, G. Issa, T. Blasco, M. Dimitrov, M. Popova, S. Hernández, D. Kovacheva, G. Atanasova, J.M. LópezNieto, Appl Catal A-Gen. 2013, 453, 1-12.

[36] Z. Liu, R. Zhou, X.J. Zheng, Energy Chem. 2008, 17, 283-287.

[37] A.P. Jia, G.S. Hu, L. Meng, Y.L. Xie, J.Q. Lu, M.F. Luo, J Catal. 2012, 289, 199-209.

[38] Y.N. Zheng, K.Z. Li, H. Wang, Y.H. Wang, D. Tian, Y.G. Wei, X. Zhu, C.H. Zeng, Y.M. Luo, J Catal. 2016, 344, 365-377.

[39] F. Bin, R. Kang, X. Wei, Q. Hao, B. Dou, P Combust Inst. 2018

[40] E. Finocchio, G. Busca, V. Lorenzelli, R.J. Willey, J Catal. 1995, 151, 204-215.

[41] S. Besselmann, E. Löffler, M. Muhler, J Mol Catal A-Chem. 2000, 162, 401-411.

[42] Y. Zhang, A. Martin, H. Berndt, B. Lücke, M. Meisel, J Mol Catal A-Chem. 1997, 118, 205-214.

[43] C. Keresszegi, D. Ferri, A.T. Mallat, A. Baikeret, J Phys Chem B. 2005, 109, 958.

[44] G. Sedmak, S. Hočevar, J. Levec, J Catal. 2004, 222, 


\section{Table of Contents}

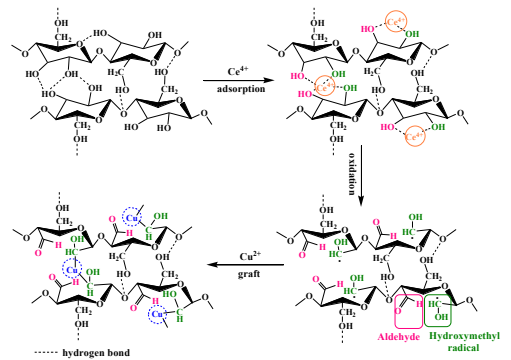

Figure 1. Schematic illustration for graft copolymerization process between $\mathrm{BC}$ and $\mathrm{Ce}^{4+}$ and $\mathrm{Cu}^{2+}$

Graft copolymerization is the addition of another monomer to the main chain of polymer, which is induced by the radical-initiated grafting. Firstly, $\mathrm{Ce}^{4+}$ is connected to $-\mathrm{OH}$ of $\mathrm{C}_{2}$ and $\mathrm{C}_{3}$ of $\mathrm{BC}$ by hydrogen-bond interaction. Secondly, the $\mathrm{C}_{2}-\mathrm{OH}$ and $\mathrm{C}_{3}-\mathrm{OH}$ of $\mathrm{BC}$ is oxidized by $\mathrm{Ce}^{4+}$ to produce hydroxymethyl radical $(\cdot \mathrm{CH}-\mathrm{OH})$ and aldehyde $(-\mathrm{CHO})$ through the electron transfer process. Finally, hydroxymethyl radical $(\cdot \mathrm{CH}-\mathrm{OH})$ can initiate $\mathrm{Cu}^{2+}$ graft by sharing electron pair effect. 
